\title{
A escola pública e as competências para o mercado: realidade e mitos
}

\author{
Saulo Rodrigues de Carvalho \\ Lígia Márcia Martins
}

\begin{abstract}
Resumo
Versar sobre a questão das competências é tratar do que há de mais recente e usual no campo da educação. O ensino de competências já adentrou as salas de aula, se incorporou ao vocabulário docente e se tornou elemento obrigatório nos planos de ensino, projetos pedagógicos e propostas curriculares. Mas em que a pedagogia centrada nas competências se diferencia das demais teorias pedagógicas, para se tornar tão fundamental à educação escolar? Por que, a cada dia, cada vez mais governos adotam o ensino de competências como estratégia e finalidade do ensino estatal? De modo geral, trataremos desses questionamentos, observando o fundamento concreto da Pedagogia das Competências, sua fundamentação filosófica e as bases políticas e econômicas que permitem a sua incorporação à prática escolar contemporânea.
\end{abstract}

Palavras-chave: Competência, pedagogia, ensino.

\section{Public school and the market : reality and myths}

\begin{abstract}
Discussing skill issues is dealing with what is most recent and usual in the field of education. Skill teaching has already entered the classroom, influenced teachers's vocabulary and has been a fixture in the educational projects and curriculum proposals. But in what aspect is pedagogy focused on skills different from other pedagogical theories to become so fundamental to schooling? Why do governments increasingly adopt skill teaching as a strategy and as goals of state education? Somehow we will treat these questions by looking at the concrete fundamentals of Skill Pedagogy Skill, its philosophical, political and economic bases to enable its incorporation into contemporary school practice.
\end{abstract}

Keywords: Competence, pedagogy, teaching.

\section{La escuela pública y las habilidades para el mercado: realidad y mitos escuela pública y mercado}

\section{Resumen}

Tratar del tema de las habilidades es considerar lo que hay de más reciente y habitual en el campo de la educación. La enseñanza de habilidades ya entró en las aulas, se incorporó al vocabulario docente y se tornó elemento obligatorio en los planes de enseñanza, proyectos pedagógicos y propuestas curriculares. Sin embargo, cómo la pedagogía centrada en las habilidades se diferencia de las demás teorías pedagógicas para hacerse tan fundamental a la educación escolar? Por qué cada día, cada vez más gobiernos adoptan la enseñanza de habilidades como estrategia y finalidad de la enseñanza estatal? Este trabajo trata de estos cuestionamientos considerando el fundamento concreto de la Pedagogía de las Habilidades, su fundamento filosófico y las bases políticas y económicas que permiten su incorporación en práctica escolar contemporánea.

Palabras clave: Competencia, pedagogía, enseñanza. 


\section{Introdução}

\section{Competências ou neotecnicismo?}

No esteio de um ideário internacional, desde a promulgação da Lei de Diretrizes e Bases Nacionais (LDB, 1996), o ensino de competências tem sido referência de inúmeros documentos estatais, a tônica de tais documentos é a recomendação do desenvolvimento de habilidades e competências como metas para a educação escolar, especialmente pública. As diretrizes que se fazem presentes neles apontam o ensino de competências como fundamento para uma formação voltada à criação de uma "moderna cidadania" que propicie a "equidade" e a "competitividade" para o "crescimento sustentável" aliado ao "progresso técnico" (CEPAL, 1992).

O discurso da modernização das práticas educativas não é um componente ideológico recente, principalmente no que tange às políticas educacionais dos países subdesenvolvidos da América Latina. Recordando, o acordo realizado durante a década de 1970 entre o Ministério da Educação e a United States Agency for Internacional Development, mais conhecido como o acordo MEC-USAID, é representativo de tais semelhanças.

Na década de 1970, os técnicos norte-americanos propunham uma educação para o Brasil que promovesse "o desenvolvimento econômico com segurança”. Nessa perspectiva, a educação deveria estar ligada diretamente à produção, uma vez que na maioria dos países desenvolvidos o crescimento econômico era explicado pela qualidade da força de trabalho consequente da educação e do progresso tecnológico (Rodrigues, 1987).

Naquele período, a política do Estado brasileiro estava voltada para a expansão da produção capitalista, comprometendo-se fundamentalmente com o crescimento da sua propriedade e produtividade e na instalação de uma base industrial que atendesse à exigência do capital internacional em seu caráter monopolista. À educação cumpriria a função de preparar os trabalhadores para se adequarem aos padrões técnicos organizativos da produção, o que demandaria uma pedagogia que se pautasse nos pressupostos da neutralidade técnico-científica, tendo por princípios a racionalidade, a eficiência e a produtividade.

Destarte, a pedagogia tecnicista despontava em unidade com a política econômica visando à padronização do ensino em vista do imperativo da máxima objetividade e racionalidade técnicas. Havia que se negar a interposição subjetiva que pudesse colocar em risco a eficiência do sistema produtivo e, nessa direção, Saviani (2008, p. 11) afirma:

(...) era mister operacionalizar os objetivos e, pelo menos em certos aspectos, mecanizar o processo. Daí a proliferação de propostas pedagógicas tais como enfoque sistêmico, o microensino, o telensino, instrução programada, as máquinas de ensinar, etc. Daí também o parcelamento do trabalho pedagógico com a especialização de funções postulando- se a introdução no sistema de ensino de técnicos dos mais diferentes matizes. Daí, enfim, a padronização do sistema de ensino a partir de esquemas de planejamento previamente formulados aos quais devem se ajustar as diferentes modalidades de disciplinas e práticas pedagógicas.

Os princípios básicos da pedagogia tecnicista eram, em larga medida, também os princípios da produção capitalista. A racionalidade, eficiência e produtividade eram pré-requisitos para o trabalho na fábrica moderna à qual o trabalhador deveria adaptar-se. Com o fim da "era de ouro do capitalismo", a pedagogia tecnicista foi revelando suas debilidades em face da necessidade de reorganização da produção, resultante das crises intermitentes do capital ao final do século $X X$.

A reestruturação produtiva gerou também uma reestruturação pedagógica mantendo a linha da eficiência e produtividade, com o acréscimo de um "tempero" ideológico muito mais elaborado do que aquele que o caráter monopolista da produção necessitava. Um arcabouço de tendências pedagógicas surge na perspectiva de um "aprender a aprender"1, necessário à adaptação dos sujeitos às transformações da sociedade, em outras palavras, adaptação dos indivíduos à crise permanente do capitalismo.

Inserida nesse arcabouço, a Pedagogia das Competências remete a um novo discurso tecnicista, todavia retirando o seu caráter racionalista, para interpor uma característica muito mais irracionalista e condizente com as necessidades dos momentos de crise do capital, qual seja, o discurso das competências para o mercado. Como descreve Carvalho (2010, p. 60):

Se já não é mais o nível de conhecimento científico que determina a posição dos indivíduos na estrutura produtiva, se as habilidades desempenhadas pelo trabalho manual, antes pertencente ao operariado, são incorporadas, cada vez com mais precisão e rapidez pela tecnologia, isentando o trabalhador dessa qualificação, então é preciso criar outro padrão que possibilite aos empresários avaliarem e absorverem a força de trabalho necessária à sua produção.

O apelo à formação das competências visa, nesse sentido, preparar os indivíduos para realizarem um tipo de trabalho não mais especializado e menos parcializado, mas com as exigências da eficiência e produtividade passadas. Extrai-se o máximo da força de trabalho dos indivíduos, atrelando-se a essa extração requisitos de sua maneira de ser e de pensar, isto é, de sua 'personalidade'. Em um processo que individualiza o êxito ou o malogro determinado pelo mercado, os trabalhadores são colocados em situação de máxima incerteza e vulnerabilidade, nas quais passam a ser avaliados por um "saber ser" e por um "saber fazer" circunscritos aos ditames do locus ocupacional que preenchem. Por outro

1 Para compreender melhor as críticas às pedagogias do aprender a aprender, ler: Duarte, N. (2006). Vigotsky e o aprender a aprender. crítica às apropriações neoliberais e pós-modernas da teoria vigotskiana. Campinas, SP: Autores Associados. 
lado, as competências requeridas, convertidas em atributos individuais, encerram um tipo de conhecimento tácito, que, se formos levar em conta a polissemia existente na palavra "tácito", podemos chamá-lo de secreto. Um conhecimento secreto que só os empresários e os especialistas da "gerência científica" conseguem reconhecer.

(O tecnicismo que se colocava antes como um acervo de técnicas a ser aprendido ressurge de maneira mais sutil como competência para "aprender a aprender" a adaptar-se às novas situações. O caráter apolítico da pedagogia tecnicista foi reelaborado por um viés pseudo-crítico, no qual passa a importar a capacidade de reflexão do indivíduo sobre a sua prática e maneira de ser, ainda que nos limites da empiria fetichizada e alienante legada aos indivíduos pela sociedade do capital.)

\section{Competências para as mudanças do mercado de trabalho}

Como podemos concluir do exposto, a pedagogia das competências se contrapõe aos métodos tradicionais de ensino baseados no processo de acúmulo de conhecimentos. Nas palavras de Perrenoud (2000, p. 15), a noção de competência designa uma "capacidade de mobilizar diversos recursos cognitivos para enfrentar um tipo de situações". As competências não são em si um tipo de conhecimento, senão uma forma de saber-fazer que se identifica com uma situação singular dada. A preocupação do ensino nessa perspectiva passa a ser o desenvolvimento de habilidades e competências necessárias para a autonomia das pessoas. Uma autonomia determinada pelas circunstâncias à vista da resolução de dada tarefa e formada por meio dos "esquemas de pensamento que permitem determinar (mais ou menos consciente e rapidamente) e realizar (de modo mais ou menos eficaz) uma ação relativamente adaptada à situação" (Perrenoud, 2000, p. 15).

Ainda que admitamos que a competência resulte na produção de uma ação adaptada a uma dada situação, cabe-nos questionar: quais são os determinantes das situações-problema que solicitam o uso das competências? Como são então determinadas as competências necessárias à resolução desses problemas?

Para alguns autores da área de educação escolar, as competências representam um aporte necessário à formação dos indivíduos no atual estágio do desenvolvimento capitalista de grandes avanços tecnológicos e científicos (Paiva, 1993). Igualmente, Giroux (1993) defende a tese de que a reestruturação produtiva das últimas décadas propiciou a "expansão de uma força de trabalho dedicada ao trabalho não-manual, numa crescente intelectualização do processo de produção”. Paiva (1993), Giroux (1993) e também Libâneo (2001) compreendem a reestruturação produtiva como um processo que resulta no aumento do trabalho intelectual em detrimento do trabalho manual. Nesse sentido, entendem que a escola deve centrar seus objetivos na formação desse perfil de trabalhador generalista e disposto por competências e habilidades necessárias ao processo produtivo.

Os referidos autores acreditam que as transformações sociais dos meios de produção e dos processos de trabalho são elementos que contribuem para uma mudança obrigatória do papel da educação escolar tendo em vista a formação de indivíduos aptos ao enfrentamento das demandas dos novos tempos. Não obstante reconhecerem nos avanços dos processos produtivos do capital os componentes da exploração e da desigualdade - que passam a ser ampliados por novos mecanismos de extração de mais-valia e seleção da força de trabalho -, esses autores consideram que a escola pode amenizar os efeitos da ação capitalista.

Libâneo (2001) observa uma relação lógica entre o desenvolvimento dos meios de produção e o desenvolvimento intelectual da força de trabalho. Para ele, o progresso científico-tecnológico das forças produtivas ocasiona, consequentemente, um maior desenvolvimento intelectual da força de trabalho. Somente nesse sentido é possível compreender sua argumentação pela adoção da metodologia do ensino de competências para o trabalho, assumidas pela escola. Se o novo tipo de trabalho é mais intelectualizado, a escola deve se preparar para formar a força de trabalho capacitada a agir na realidade "de forma crítica e criativa".

Contudo, Libâneo não analisa a contradição existente entre os meios de produção e a força de trabalho no sistema capitalista. Concretamente, o incremento da produtividade tem levado a uma queda tendencial do emprego da força de trabalho. Os "fatores objetivos" (os meios de produção) tendem a reduzir a interferência dos "fatores subjetivos" (a força de trabalho) no processo de produção (Marx, 2002). Essa relação fica mais clara quando se compreende que o desenvolvimento da produção capitalista, seus fatores objetivos têm essencialmente a função de aumentar a exploração sobre a força de trabalho, ou seja, ampliar a extração da mais-valia, para se colocar a questão em termos marxianos.

Logo, temos uma situação inversa ao que Giroux (1993) e Libâneo (2001) compreendem como a atual. As novas tecnologias tendem a incorporar o conhecimento e as habilidades, antes pertencentes à força de trabalho, ao capital - diz Marx (2002): "incorpora(m) a ciência e as forças da natureza" para torná-las suas. Não é sem motivo que, nas grandes montadoras de automóveis, galpões inteiros desapareceram para dar lugar às Células Flexíveis de Manufatura. Profissões especializadas, como a do ajustador mecânico, torneiro, fresador, ferramenteiro, deixaram de existir para dar lugar ao mecânico geral, que, como o nome diz, é um profissional generalista, menos especializado em uma só função ou maquinaria.

Essas profissões, que antes exigiam um conhecimento específico e dado grau de habilidades dos profissionais, tiveram suas especialidades incorporadas em grande medida pela tecnologia dos Comandos Numéricos Computadorizados (CNCs), que nada mais são do que uma espécie de amálgama entre a interface lógico-binária da computação e os comandos mecânicos, hidráulicos e pneumáticos convencionais. Um maquinário de alta precisão munido de 
uma base de dados que memoriza e executa operações de maneira automatizada, em grandes quantidades e com uma perfeição que as mãos humanas não conseguem alcançar. Há menos de vinte anos tínhamos montadoras ${ }^{2}$ que empregavam cerca de 20 mil funcionários, já atualmente a grande indústria automobilística constrói fábricas que não ultrapassam o contrato de 5 mil funcionários, obtendo ainda assim o dobro da produtividade dos anos atrás. Uma economia extraordinária com a força de trabalho.

Mas essa economia não se dá apenas na quantidade da força de trabalho necessária à produção, ela pode ser verificada também na qualidade dessa força de trabalho, ou seja, no tempo gasto para a qualificação dos trabalhadores. Vejamos, um bom especialista demorava em média 20 anos para atingir o alto nível de produtividade e excelência que as empresas necessitavam. Esses trabalhadores até duas a três décadas atrás eram altamente valorizados em razão de sua experiência. Atualmente as empresas não necessitam mais dessa força de trabalho especializada, pois suas funções são executadas por máquinas computadorizadas que conseguem trabalhar horas a fio, mantendo um nível de qualidade superior ao que os velhos torneiros mecânicos conseguiriam.

Mas, como a máquina não faz tudo sozinha, é preciso alguém para operá-la. É aí que ocorre a grande ilusão a respeito da força de trabalho necessária para operar esse novo maquinário. Muitos teóricos confundem o conhecimento da interface do sistema computadorizado da máquina com um tipo de conhecimento mais intelectualizado. É verdade que existe certa exigência para operar tais tecnologias, todavia, na maioria das vezes, esse tipo de operação não ultrapassa ações pragmáticas e facilmente treináveis. Um indivíduo é instruído sobre os comandos necessários para realizar tal operação e assim o faz até que novos comandos lhe sejam ordenados.

Um profissional médio com certo grau de conhecimentos em informática, matemática e interpretação de texto já é o bastante para formar esse tipo de força de trabalho. A aparente intelectualidade dos profissionais de "qualificação técnica mais elevada" não se manifesta efetivamente no momento da produção. Isso porque a nova produção é projetada para "otimizar" ao máximo o trabalho. Significa que o trabalho deve ser concluído no menor tempo possível com o máximo da qualidade.

Neste tipo de organização da produção, as operações dos trabalhadores são anteriormente planejadas para que tenham um maior aproveitamento do tempo. As máquinas e os postos de trabalho são preparados para que os operários desempenhem sua função com a máxima produtividade. Uma produção organizada para que o trabalhador pense o mínimo necessário em suas tarefas e apenas execute o que for preciso para atingir suas metas. Ademais, a ideia de um trabalho mais intelectualizado com a reestruturação produ-

2 O exemplo das montadoras é o mais notório, porém a reestruturação produtiva atingiu não só a indústria automobilística, mas a base industrial como um todo, desde a indústria leve, as agroindústrias, até a indústria pesada. tiva não é totalmente descartável, mas é preciso observá-la não como a superação do trabalho manual, mas como uma característica do aprofundamento da divisão do trabalho.

Consideramos que apenas por uma ilusão de ótica os avanços resultantes da reestruturação produtiva podem ser associados a melhorias na condição de trabalhador. A referida reestruturação, pelo contrário, representa formas cada vez mais sutis de intensificação e exploração do trabalho. Há que se observar, porém, que a análise em curso não se coloca como apelo saudosista às condições de trabalho do passado e nem como apologia da manufatura em detrimento dos avanços científicos e tecnológicos contemporâneos.

A promessa da ampliação da qualificação educacional dos trabalhadores na reestruturação produtiva implica tanto mais o alargamento do controle do que a emancipação do trabalho e compreensão de sua totalidade. As contradições presentes na formação da força de trabalho nessa nova configuração do capital simplesmente se acirraram. O que está em jogo é, substancialmente, a diminuição dos postos de trabalho e a redução do poder da classe trabalhadora. O controle exercido pela racionalidade técnica estende-se também ao trabalhador, cada vez mais premido pelas estratégias de controle tanto interno - exercido pelo sistema de gestão de pessoas - quanto externo - representado pela crescente redução da empregabilidade.

A reestruturação produtiva é, por outro lado, um reflexo do acréscimo exponencial da propriedade capitalista, do seu "Capital Constante" (Marx, 2002), e o emprego é cada vez mais reduzido da força de trabalho (sua intensificação) no aumento das taxas de mais-valia. Nessa configuração, a absorção da maior parte da força de trabalho está locada em pontos que exijam baixa qualificação, ligados a empresas terceirizadas e setores de serviço. Como aponta Alves (2002, p. 84):

O crescimento das empresas de trabalhos temporários e de trabalhadores domésticos demonstra a inserção crescente de um contingente maciço de jovens, homens e mulheres no mercado de trabalho de maneira precária, vendendo sua força de trabalho para a indústria, bancos e comércio por tempo parcial e determinado. Em sua maioria pertencem aos contingentes de trabalhadores ocupados pelo setor privado que não possuem cobertura da Previdência Social, ou seja, não têm direito à aposentadoria e nem auxílio-doença.

Com o capital empregando cada vez menos força de trabalho, fica cada vez mais restrita a seleção de trabalhadores. Por outro lado, a massa de desempregados permite um poder extraordinário para o rebaixamento do valor da força de trabalho. Aliado a isso tudo, uma crise de civilidade solapa as bases da vida social, determinando a aplicação crescente de mecanismos de controle políticos e ideológicos que possam, em larga medida, amenizar as contradições advindas das crises estruturais. Por essa via, o autoritarismo também se vê ampliado pelas relações de poder que pautam a reestruturação produtiva. 


\section{A ideologia das competências ou a competência da ideologia?}

Procuramos demonstrar em quais bases materiais a Pedagogia das Competências se fundamenta. Ela surge num momento ímpar da produção capitalista, quando um número cada vez mais reduzido de força de trabalho empregada consegue atingir altos níveis de produtividade em função do grande desenvolvimento científico e tecnológico, o que tem tornado a produção mais independente das qualificações dos trabalhadores, padronizando uma força de trabalho que seja intercambiável e flexível.

Isso torna o discurso do ensino de competências muito poderoso, pois são agora os "esquemas de pensamento" que serão avaliados e não necessariamente os conhecimentos sobre determinado assunto ou objeto. Segundo Perrenoud (2000, p. 16),

(...) os esquemas de pensamento não são diretamente observáveis e só podem ser inferidos a partir das práticas e dos propósitos dos atores. Além disso, é difícil considerar a inteligência geral do autor - sua lógica natural - e os esquemas de pensamento específicos desenvolvidos no âmbito de uma especialização particular. Intuitivamente, pressentimos que o professor desenvolve esquemas de pensamento próprios a seu ofício, diferentes daqueles do piloto, do jogador de xadrez, do cirurgião ou do corretor. Falta descrevê-los mais concretamente (grifo nosso).

Nesse excerto, Perrenoud confirma a falta de objetividade e o solipsismo presentes na observação dos "esquemas de pensamento", ou seja, na avaliação das competências. Isso permite um grau de parcialidade muito grande por parte de quem avalia uma determinada competência. Essa parcialidade se concretiza à medida que, frente à crise do emprego, o que mais se relata é a falta de profissionais qualificados e não a redução dos parques industriais e o "enxugamento" das empresas (Chesnais, 1996).

Desse modo, a Pedagogia das Competências, estruturalmente vinculada às relações econômicas, exerce uma função ideológica que equivale a desviar o foco das tensões produzidas pela crise geral do modo de produção capitalista, individualizando-a. Consequentemente, torna-se necessário aos indivíduos buscarem alternativas para se adaptarem à crise permanente do sistema. Cabe observar que, não raro, os empresários da educação, tomando o ensino de competências como mais um filão de mercado, exploram-no em cursos de formação contínua voltados à inserção ou ascensão no mercado.

Martins (2004) também destaca que a noção de competência permeia o discurso do ensino para qualificação profissional, "tão bem entalhada pela ideologia da empregabilidade" (p. 54). No discurso escolar, aprender competências transforma-se num elemento fundamental para a garantia do emprego. Só não se sabe para qual emprego.

A competência dessa ideologia, parafraseando o subtítulo desse texto, encontra-se justamente na sua inter- -relação com a vida cotidiana dos indivíduos, na necessidade intrínseca de reproduzirem suas vidas por meio do trabalho. É a "consciência prática", e por que não pragmática, de um sociometabolismo em crise (Mészaros, 2002).

Nesse sentido, a competência como conceito de ensino é uma ideologia que se renova parecendo incorporar os anseios da "classe rival" do capital, apresentando um ensino aparentemente preocupado com a formação geral dos indivíduos e com o maior desenvolvimento da sua intelectualidade. Aparentemente, visa preparar para trabalhos que não sejam mais "repetitivos" e "alienantes" - representados pela figura dos especialistas das linhas de montagem fordistas - tendo em vista adentrarem ao modelo de trabalho e de fábrica flexível, no qual os trabalhadores têm a noção da "totalidade" da sua produção.

Seria minimamente questionador imaginar que os empresários estejam realmente preocupados com a melhoria das condições de trabalho e da capacidade intelectual dos trabalhadores. Mas é o que muitos estudiosos da educação, inclusive de "esquerda" (ou que em algum momento da vida foram de esquerda), consideram. Ainda que apresentem que isso seja uma necessidade do sistema para ampliar o processo de acumulação, não nos parece convincente, analisando as bases da produção, que esse seja realmente o interesse de empresários e/ou de governos ao proporem a educação com fundamentos na Pedagogia das Competências.

É só descermos um pouco ao "chão de fábrica" para percebermos como esse discurso das competências para o trabalho realiza um objetivo inversamente contrário ao da sua definição teórica. Os maravilhados com a "revolução informacional" e automação das máquinas esquecem que "(...) No controle numérico, exige-se pouca habilidade do operador e um único operador pode supervisionar mais de uma máquina" (Pereira, 2008, p. 11). A máquina, como descreve esse autor em uma apostila para a formação de Técnicos em Eletromecânica: "1 nunca reclama; 2 nunca entra em greve; 3 não pede aumento de salário; 4 não precisa de férias [e] 5 não requer mordomias" (Idem, p. 5).

Esse seria o melhor dos mundos do capitalismo, sem reclamações, sem greves, sem aumentos de salário, sem férias, sem mordomias! Não fosse o fato de que, inevitavelmente, todo esse maquinário e tecnologia não passem de "trabalho morto", ou melhor, de "Capital Constante" (Marx, 2002), que não pode fazer outra coisa senão transferir uma parte do seu valor para a produção de mercadorias, que não pode gerar novos valores sem o componente da força de trabalho humana.

Para ilustrar essa relação, podemos encontrar ainda, na mesma apostila de Técnicos em Eletromecânica, uma justificativa que é quase um lamento em face do inconveniente emprego da força de trabalho para supervisionar a máquina:

Como nada é perfeito a máquina tem as seguintes limitações: 1 capacidade limitada de tomar decisões; 2 deve ser programada ou ajustada para controlar sua operação nas 
condições especificadas; 3 necessita de calibração periódica para garantir sua exatidão nominal; 4 requer manutenção eventual para assegurar que sua precisão nominal não se degrade (Pereira, 2008, p. 5).

É implícito o desprezo pelo trabalhador, que se torna apenas um apêndice da máquina. Contudo, essa aversão pelo trabalho manual e o seu quase total ocultamento pela reestruturação produtiva formam o pivô da supressão das garantias de emprego, desregulamentação das formalidades do trabalho e revisão do valor da força de trabalho sempre em baixa. A flexibilização do trabalho e a formação de competências de maneira alguma posicionam a escola numa posição unitária ${ }^{3}$, ao contrário, têm levado o ensino para uma posição inescrupulosamente unilateral da formação de competências e habilidades que "os empresários esperam dos futuros funcionários".

\section{Pedagogia das Competências e a renovação da Teoria do Capital Humano}

Muito difundida nas décadas de 1960 e 1970, a Teoria do Capital Humano ainda exerce uma grande influência sobre as necessidades educacionais tanto na esfera macro, na adoção de métodos e sistemas educacionais dos Governos Nacionais e Estados, como na esfera micro, nas escolhas pessoais dos indivíduos naquilo que se referem à sua formação educacional.

Basicamente, a Teoria do Capital Humano vincula o crescimento econômico dos países mais desenvolvidos ao investimento em educação. Também, para essa teoria, a melhoria das condições de vida dos trabalhadores desses países seria resultado de investimentos individuais das pessoas na melhoria de seu currículo educacional. Com isso, a qualidade da educação não deixa de ser um elemento marginal, embora se afirme a educação, em si mesma, como um fator que agrega valor à força de trabalho.

Retiradas todas as variáveis que denotam a divisão de classes no substrato da sociedade burguesa, a teoria do capital humano recoloca os indivíduos em posição de uma igualdade abstrata, uma vez que todos são, em tese, capazes de aprender. O sucesso ou fracasso de cada um passa a se determinar, cada vez mais, pela disposição individual de investimento em si como capital humano. Tal assertiva se aplica também aos governos e países que se preocupam com o aumento da produtividade e do bem-estar de seus concidadãos - que os mesmos invistam no capital humano da sua força de trabalho como pré-requisito para entrarem na seleta lista de países desenvolvidos.

No mundo dos economistas burgueses, a educação da força de trabalho torna-se o fator primordial para o au-

3 Já nos referimos na primeira parte deste texto à visão de Libâneo (2001) sobre a reestruturação produtiva, mas vale aqui ressaltar que ele procura cogitar que a flexibilização do trabalho e a suposta intelectualização dos trabalhadores permitem pensar a ideia gramsciana de Escola Unitária. mento da geração de riquezas. Supostamente, o problema não radica na exploração exercida pela indústria capitalista, nem no trabalho excedente produzido pelos trabalhadores como um todo, mas sim na educação individual e capacitação para o trabalho, que se tornam fatores centrais para a explicação da desigualdade econômica entre os indivíduos e entre as nações. Num período de grande expansão do capital e auge do capital monopolista, essa teoria exerceu uma grande força material na legitimação de programas educacionais implantados nos países subdesenvolvidos, destinados ao treino e domesticação da força de trabalho.

Evidente que, com as crises que já no final da década de 1970 abalaram os alicerces da economia capitalista, a Teoria do Capital Humano não conseguiria permanecer de pé por muito tempo. Mas também é claro que uma teoria como essa não se extinguiria assim tão depressa sem deixar vestígios. Oriundas dessa explicação das relações econômicas e da educação, outras tendências se formaram. Santos (2011) aponta que a herdeira mais próxima da Teoria do Capital Humano seria a teoria do Capital Intelectual. Na Teoria do Capital Intelectual, os investimentos que antes eram de responsabilidade do Estado passam agora a vigorar nas mãos do poder privado. Entram em ação as políticas neoliberais de privatização e "publicização" do ensino. No Brasil identificamos facilmente esse período com a expansão das faculdades particulares beneficiadas pelas políticas de Paulo Renato, então ministro da educação na era FHC.

Com a flexibilização das relações de trabalho e consequente redução dos postos formais de emprego, novas exigências foram criadas para compor os mecanismos de competição e exclusão do mercado de trabalho. Junto a isso, a formatação de um lucrativo mercado da educação, que retira das mãos do Estado parte do seu privilégio na educação da força de trabalho (Santos, 2011).

Embora apresentem diferenças de fundo quanto ao financiamento e às exigências para a qualificação do mercado de trabalho, as teorias do Capital Humano e do Capital Intelectual mantêm as mesmas bases ideológicas referentes ao papel econômico da educação na geração de riqueza e mobilidade social.

Basicamente, consideramos que, por esse caminho, alcançamos a gênese da pedagogia das competências, que se desenvolve sobre a base político-econômica do capital em crise, apresentando-se não como uma ruptura do tecnicismo e do modelo fordista de produção, mas como uma continuidade de seu fundamento ideológico.

O discurso da melhoria das qualificações para o trabalho, que, na Teoria do Capital Humano era a fonte explicativa para a ascensão social dos trabalhadores no auge do welfare states, no capitalismo em crise torna-se - camuflado em novas teorias - a explicação para o desemprego e subemprego de um contingente enorme de trabalhadores arrancados dos postos de trabalho pela reestruturação produtiva.

Na nova roupagem da Teoria do Capital Humano, a qualificação técnica cede espaço para a noção de competência. Mas a competência não se destina à educação dos 
trabalhadores no seu maior nível intelectual, nem nas suas mais avançadas concepções técnico-científicas. É, de outro modo, uma educação de caráter subjetivista que mais se assemelha a técnicas de autoajuda, tal como desenvolvidas pelos setores de Recursos Humanos das empresas. Isso porque na base das competências não estão os saberes universais, que foram submetidos a comprovações científicas e à validação histórica, mas sim procedimentos operacionais adequados às necessidades da situação. Nesse sentido, segundo o pensamento hegemônico, a escola não precisa ensinar os saberes universais, porque eles já estão constituídos e acessíveis por meio da comunicação e da tecnologia informacional. É preciso, então, ensinar os indivíduos a buscarem e a mobilizarem esses conhecimentos, se e quando necessário.

As competências tornam os trabalhadores multifuncionais, isso significa que é preciso que o indivíduo apreenda com rapidez a executar novas e diversificadas tarefas sempre que requeridas. $\mathrm{O}$ ensino pelas competências também não pressupõe a igualdade do conhecimento. Isso porque não se ensinam conteúdos, mas formas de aprendê-los. O lema de Comenius de "ensinar tudo a todos" é substituído pelo "aprender a aprender", e a competência transforma-se num artifício que possibilita a aplicação desse novo dizer, ficando a cargo de cada um procurar aprender o conhecimento que melhor the aprouver.

Não é um indivíduo intelectualizado e erudizado que o mercado quer, mas o trabalhador que tenha "jogo de cintura" para aceitar e se adequar às mudanças constantes da produção flexível. Em outras palavras, o ideário das competências forma trabalhadores para o subemprego, para a sobrevivência do mercado em crise, para a instabilidade do capitalismo contemporâneo.

Uma vez que a reestruturação produtiva possibilitou certa uniformização das qualificações técnicas dos trabalhadores, proporcionou grande vantagem à classe dominante no conflito entre o capital e o trabalho, fazendo valer o mote de que "não há ninguém insubstituível". Hoje é muito mais simples para o capitalista substituir um trabalhador generalista da fábrica flexível do que era antigamente com os especialistas na produção fordista-taylorista. Não é preciso, atualmente, encontrar alguém que saiba fazer determinada atividade específica, pelo contrário, precisa-se de alguém que esteja disposto a fazer várias atividades sem conhecer, aprofundadamente, nenhuma.

É interessante observar que, na heterogeneidade das funções no modelo fordista-taylorista - na qual cada trabalhador deveria ser especialista em sua função -, a competição entre os trabalhadores tinha menor intensidade do que atualmente. Na coletividade da empresa, cada função era extremamente dependente de outras, fator que contribuía positivamente nas negociações coletivas entre empregados e empregadores. Com a homogeneização das funções, na qual todos fazem tudo, a competição entre os trabalhadores tende a ser maior e as negociações coletivas mais enfraquecidas, já que, independentes uma das outras, as funções que eventualmente deixem de ser exercidas por determina- da pessoa, ou determinado setor da empresa, podem ser realizadas por outra pessoa ou setor, que conseguem sem muitas dificuldades acumular funções.

A gestão organizacional, orientada pela ótica hegemônica, muito tem se esforçado por construir esse espírito adesista no âmbito interno das organizações. Apelos ao novo papel do líder, que, em substituição ao supervisor fordista-taylorista, não tem a função de "controlar", mas de "motivar", de realizar atividades de dinâmica de grupo, reuniões e seminários de motivação e sensibilização, revelam essa relação de cooptação, ou outra forma de controle, o da subjetividade (Santos, 2011, p. 9).

O imperativo da empregabilidade sustenta o discurso da reformulação da educação dos indivíduos, calcado agora sob a aparência da competência. Os conhecimentos escolares, os conteúdos das ciências, das artes, da filosofia tornam-se secundários para esse tipo de currículo fundado no desenvolvimento das características "cognitivas" e "afetivas", como se isso fosse possível na ausência de uma sólida formação acadêmica.

Esperamos ter demonstrado as matizes ideológicas da Pedagogia das Competências, cuja matriz histórica aponta os preceitos da Teoria do Capital Humano, ainda que ornamentando suas variações políticas e ideológicas. Defendemos, portanto, que seu surgimento não decorre do beneficiamento das inovações tecnológicas, mas das necessidades estruturais de um capitalismo em crise, ou seja, da renovação ideológica do pensamento econômico neoclássico da Teoria do Capital Humano.

\section{Considerações finais}

Pelo exposto, depreende-se que a realidade que se reflete nas proposições da Pedagogia das Competências aponta a profunda crise gerada pelo capital em relação ao direito humano pelo trabalho. Todavia, tal fato é assustador em demasia para que possa ser explicitado objetivamente e, consequentemente, há que se mistificá-lo.

O discurso sedutor, pseudo-humanista e adaptativo que permeia as premissas desse ideário ecoa como ideal para a formação de indivíduos à altura das novas demandas do século $\mathrm{XXI}$, obscurecendo que o que está em curso nele - em nome de uma sociedade pós-moderna - é mais uma estratégia de reificação da pessoa humana.

Portanto, subjugar a educação escolar ao ensino de competências, mais que promover o seu esvaziamento, significa aliená-la de sua função precípua, qual seja: corroborar para a formação das novas gerações por meio da transmissão dos conhecimentos historicamente sistematizados, possibilitando-lhes a conquista das máximas capacidades humanas.

A crítica ora em curso não se apoia no princípio ingênuo de que, na sociedade capitalista, a educação escolar possa ou deva furtar-se à tarefa de preparar os indivíduos 
para o mercado de trabalho. Esse preparo, porém, não pode se limitar aos ditames do capital, em simplesmente preparar os indivíduos para serem meros coadjuvantes da produção capitalista, mas formá-los para serem sujeitos da transformação social. Isso implica um processo de conhecimento profundo da realidade da sociedade de classes, da exploração existente, dos seus mecanismos de controle e, por fim, das suas formas de superação. Ou seja, implica um processo de formação da consciência crítica.

Todavia, a perspectiva de formação hegemônica se mostra insuficiente para promover, de fato, uma sólida formação escolar, posto que a mesma resulta da apropriação de conteúdos de outra natureza, quais sejam, dos domínios científicos, éticos e estéticos que elevem os indivíduos para além das amarras da vida cotidiana possibilitando-Ihes, inclusive, um outro projeto de sociedade.

Como resultado da descaracterização da função essencial da escola em nome de um apologético "aprender a aprender" e em nome de um suposto desenvolvimento de competências, acompanhamos a passos largos a conversão do espaço escolar em palco de violência, indisciplina e adoecimento de várias ordens.

Para a superação desse quadro de degradação, urge romper os mitos, encarar a realidade e recuperar a função social da escola na luta entre sua condição de instituição determinada, mas também determinante das formas de sociabilidade humana (Saviani, 2008). Caso contrário, os discursos vazios e sedutores que assolam o espaço escolar continuarão imperando e corroborando para a preservação da vida social exatamente naquilo que ela tem de pior: a exploração do homem pelo homem.

\section{Referências:}

Alves, G. (2002). Trabalho e sindicalismo no Brasil: um balanço crítico da "década neoliberal" (1990-2000). Revista Sociologia Política, 19, 71-94.

Carvalho, S. R. (2010). Políticas neoliberais e educação pós-moderna no ensino paulista. Dissertação de Mestrado, Universidade Estadual Paulista Júlio de Mesquita Filho, Araraquara, São Paulo.

Comissão Econômica para a América Latina - CEPAL. (1992). Educación y conocimiento: eje de la transformación produtiva com equidad. Santiago do Chile: UNESCO.

Chesnais, F. (1996). A mundialização do capital. São Paulo: Xamã.
Duarte, N. (2006). Vigotsky e o "aprender a aprender": crítica às apropriações neoliberais e pós-modernas da teoria vigotskiana. Campinas, SP: Autores Associados.

Giroux, H. (1993). O pós-modernismo e o discurso da crítica educacional. Em T. T. Silva (Org.), Teoria educacional crítica em tempos pós-modernos (p. 36-58). Porto Alegre: Artes Médicas.

Lei n. 9.394, de 20 de dezembro de 1996. (1996, 23 de dezembro). Estabelece as Diretrizes e Bases da Educação Nacional. Diário Oficial da União, seção 1.

Libâneo, J. C. (2001). Pedagogia e pedagogos, para quê? São Paulo: Cortez.

Martins, L. M. (2004). Da formação humana em Marx à crítica da pedagogia das competências. Em N. Duarte (Org.), Crítica ao fetichismo da individualidade (pp. 51-73). Campinas,SP: Autores Associados.

Marx, K. (2002). O Capital (Livro1, Vol. I). Rio de Janeiro: Civilização Brasileira.

Mészáros, I. (2002). Para além do capital. São Paulo: Boitempo.

Paiva, V. P (1993). O novo paradigma de desenvolvimento: educação, cidadania e trabalho. Educação e Sociedade, 45, 85-112.

Pereira, J. P. P. (2008). Curso técnico de nível médio subsequente em eletromecânica: automação de sistemas industriais. Natal: Funcern.

Perrenoud, P. (2000). 10 novas competências para ensinar. Porto Alegre: Artmed.

Rodrigues, N. (1987). Estado, educação e desenvolvimento econômico. São Paulo: Autores Associados / Cortez.

Santos, A. F. T. (2011). Teoria do Capital Intelectual e Teoria do Capital Humano: estado, capital e trabalho na política educacional em dois momentos do processo de acumulação. Anais eletrônicos, XXVII Reunião Anual da ANPEd. Caxambu, MG. Recuperado: 19 dez. 2011. Disponível: http://www.anped.org.br/reunioes/27/gt09/ t095.pdf

Saviani, D. (2008). Escola e democracia. Campinas, SP: Autores Associados. 
Recebido em: 22/03/2012

Reformulado em: 15/06/2012

Aprovado em: 22/06/2012

Sobre os autores

Saulo Rodrigues de Carvalho (saulorc1982@gmail.com)

Professor do curso de Pedagogia da Universidade Federal do Amazonas (UFAM) - ICSEZ/ Parintins-AM. Mestre em Educação Escolar pela Universidade Estadual Paulista (UNESP) - Araraquara-SP.

Endereço postal: Estrada Parintins- Macurany, S/N. Jacareacanga, CEP: 69152-450, Parintins, AM - Brasil.

Lígia Márcia Martins (ligiamar@fc.unesp.br)

Livre Docente em Psicologia da Educação e Doutora em Educação pela UNESP. Professora do curso de Graduação em Psicologia da Faculdade de Ciências, UNESP/Bauru e do Programa de Pós-Graduação em Educação Escolar da Faculdade de Ciências e Letras da UNESP/Araraquara. Membro do Grupo de Pesquisa "Estudos Marxistas em Educação".

Endereço: Av. Edmundo Coube, 14-01, Vargem Limpa, CEP: 17033-360, Bauru/SP.

Escola pública e mercado * Saulo Rodrigues de Carvalho e Lígia Márcia Martins 
